Should be cited as: Ranius, T., Korosuo, A., Roberge, J.-M., Juutinen, A., Mönkkönen, M., Schroeder, M. (2016) Costefficient strategies to preserve dead wood-dependent species in a managed forest landscape. Biol. Conserv. 204: 197-204.

Available at: http://dx.doi.org/10.1016/j.biocon.2016.10.017

\title{
Cost-efficient strategies to preserve dead wood-dependent species in a managed forest landscape
}

\author{
Thomas Ranius $^{1, *}$, Anu Korosuo ${ }^{2,3}$, Jean-Michel Roberge ${ }^{4}$, Artti Juutinen ${ }^{5}$, Mikko \\ Mönkkönen ${ }^{6}$, Martin Schroeder ${ }^{1}$ \\ ${ }^{1}$ Dept. of Ecology, Swedish University of Agricultural Sciences, Box 7044, 75070 Uppsala, Sweden \\ ${ }^{2}$ Dept. of Forest Resource Management, Swedish University of Agricultural Sciences, 90183 Umeå, Sweden \\ ${ }^{3}$ Present address: Ecosystems Services and Management Program, International Institute for Applied \\ Systems Analysis, Schlossplatz 1, A-2361 Laxenburg, Austria \\ ${ }^{4}$ Dept. of Wildlife, Fish and Environmental Studies, Swedish University of Agricultural Sciences, 90183 \\ Umeå, Sweden \\ ${ }^{5}$ Dept. of Economics, University of Oulu, Box 4600, 90014 Finland \\ ${ }^{6}$ Dept. of Biological and Environmental Science, University of Jyväskylä, P.O. Box 35, Jyväskylä 40014 , \\ Finland \\ * Address correspondence to Thomas Ranius, email: thomas.ranius@slu.se; telephone: +46-18-672334
}

\begin{abstract}
Negative consequences of intensive forest management on biodiversity are often mitigated by setting aside old forest, but alternative strategies have been suggested. We have compared with simulations the consequences of two of these alternatives - setting aside young forests or extending rotation periods - to that of current practice in managed boreal forest. In all scenarios we applied a constant conservation budget and predicted forest development and harvesting over 200 years. As a proxy for biodiversity conservation, we projected the extinction risk of a dead wood-dependent beetle, Diacanthous undulatus, in a $50 \mathrm{~km}^{2}$ landscape in central Sweden, using a colonization-extinction model. During the first century, setting aside young forest stands rather than old stands increased extinction risk because young stands have lower habitat quality. However, habitat quality of young forests increased as they aged and they were much cheaper to set aside than old stands. Therefore, the strategy allowed a larger set-aside area (within the budget constraint), resulting in lower extinction risk and harvested timber volumes in the second century. Prolonging rotations also decreased the extinction risk but was in the long term less costeffective. The most cost-effective strategy in the long term (200 years) was to set aside a mixture of old and young forest. However, setting aside young stands rather than prolonging rotations or setting aside old stands delays both the benefits (lower extinction risk) and costs (lost harvest volumes), so the optimal strategy depends on the assumed societal values and hence discount rates.
\end{abstract}


Keywords: conservation strategy, discounting, forest age, population viability, prolonged rotation, time horizon

\section{Introduction}

Intensive forest production has modified forests worldwide, often with strongly negative effects on biodiversity (Secretariat of the Convention on Biological Diversity 2010). Since maintenance of biodiversity is regarded as an important goal in sustainable forestry, efforts are made to mitigate these effects (Lindenmayer and Franklin 2002). The underlying policies often aim at maintaining species populations that are viable in the long term (e.g. in the Swedish Environmental objectives: Anonymous 2016). This is often done by establishing set-asides (i.e. conservation areas exempt from timber extraction), typically to protect biodiversity 'hotspots' in order to maximize current species richness within budgetary and other socio-economic constraints (e.g. Virolainen et al. 2000). However, especially in landscapes with little remaining unmanaged forest, such a strategy may result in small and isolated protected areas, often providing poor prospects for long-term viability of some species' populations (Öckinger and Nilsson 2010). Thus, to evaluate the consequences of conservation strategies on biodiversity, it is important to adopt a long temporal perspective, meaning that more than one rotation should be included, which is typically more than a century in northern forests (Ranius and Roberge 2011). Furthermore, it is often crucial to recognize that habitats are dynamic, and that suitable habitats for forest species may occur not only in protected areas, but also in managed production forest matrices (e.g. Lindenmayer and Franklin 2002, Schroeder et al. 2007). Therefore, both species and habitat dynamics as well as both production and set-aside forests should be considered when evaluating effects of conservation strategies on biodiversity in forest landscapes.

In the even-aged forest management systems dominating in many parts of the world, forest stands are harvested by clearcutting and then actively regenerated. In such managed forest landscapes, old forest covers smaller areas than in naturally-dynamic forest landscapes (Lindenmayer and Franklin 2002). This impairs biodiversity, because forests in later successional stages contain structures and species that are rare or absent in younger forests (Lassauce et al. 2013). Therefore, older forests have been traditionally prioritized 
over younger ones when selecting set-asides (Gustafsson and Perhans 2010). However, results from two recent analyses suggest that it may be more cost-efficient, in terms of conservation benefits that can be obtained with a given budget, to set-aside young forests (Lundström et al. 2016; Mazziotta et al. 2016). This is mainly because timber products cannot be extracted from young forests for several decades, so they are much cheaper to set aside than mature stands. However, the cited studies did not address two factors which must be considered in comprehensive assessments of the consequences of setting aside young forests for biodiversity and forestry: (1) persistence of species’ populations and (2) future levels of harvestable timber volumes.

Rotations are sometimes prolonged in managed forest in order to promote biodiversity (Lassauce et al. 2013). This increases amounts of habitats for species that require structures associated with old trees and large-diameter dead wood (Jonsson et al. 2006; Lassauce et al. 2013), especially if the prolonged rotations are not accompanied by extra thinnings (Roberge et al. 2016). Thus, prolonging rotations increases landscape-scale habitat availability for various taxa that might otherwise be threatened (Jonsson et al. 2006; Juutinen et al. 2014; Mönkkönen et al. 2014). Moreover, prolonged rotations increase the length of the temporal window when conditions are suitable for these species, which may strongly improve their persistence by favorably changing the relationship between colonization and extinction rates (Keymer et al. 2000). However, we are not aware of any published analysis of prolonging rotations' effects on colonization-extinction dynamics and hence population persistence.

The aims of this study are to elucidate the long-term biodiversity consequences of setting aside young forests and prolonging rotations in managed forest landscapes, including hitherto neglected effects on population persistence and levels of harvestable timber volumes. By projecting forest development and population dynamics over 200 years in a managed forest landscape in central Sweden, and comparing outcomes with those of a scenario with no conservation efforts, we evaluate the following four strategies for conserving biodiversity: setting aside old stands, young stands, or mixtures of old and young stands, and prolonging the rotations. We consider three responses: timber production (i.e. the total harvested volume of trees), habitat availability, and population persistence of a focal species. The budget, in terms of net present value of timber (NPV), is 
kept constant in all scenarios. The focal species is a previously red-listed beetle, Diacanthous undulatus, which inhabits dead wood. Its population persistence is projected using a colonization-extinction model that we developed from presence/absence data collected in the considered landscape. Diacanthous undulatus occurs both on clear-cuts and in old (managed and unmanaged) forests, but 10-60 year-old managed forests offer little or no habitat for the species. Hence, by using this focal species we acknowledge that both managed and unmanaged forests, and young as well as old forests, may be important for the conservation of forest species. Since the species model used is dynamic, the outcome reflects not only habitat availability but also effects of colonization-extinction dynamics.

\section{Methods}

\subsection{Study landscape}

The simulations were based on data collected in the Delsbo area, central Sweden $\left(62^{\circ} \mathrm{N}\right.$, $16^{\circ}$ E). We used $D$. undulatus (formerly Harminius undulatus) occurrence data collected in 68 forest stands in a $28 \times 28 \mathrm{~km}^{2}$ block of land including a $4 \mathrm{~km}$ wide buffer zone (Schroeder et al. 2007). Our predictions of species persistence and forest production considered a $50 \mathrm{~km}^{2}$ square located within that block of land. Most (80\%) of the Delsbo area is covered by productive forests (i.e. forests with annual wood volume growth exceeding $1 \mathrm{~m}^{3} / \mathrm{ha}$ ). The landscape is typical for the Swedish boreal region, with Scots pine (Pinus sylvestris L.) and Norway spruce (Picea abies (L.) Karsten) being the dominant tree species. The height above sea level varies from $140 \mathrm{~m}$ to $530 \mathrm{~m}$. Currently, most forest stands in the area are constituents of the first generation of even-aged forest created by clear-cut harvesting. The average volume of dead wood in the managed stands is $13.8 \mathrm{~m}^{3}$ $\mathrm{ha}^{-1}$, about twice as high as the Swedish average (Ekbom et al. 2006). The industrial forest owners (Holmen Skog AB and Bergvik Skog AB) have been FSC-certified since the late 1990s, and thus follow the requirements to set aside $\geq 5 \%$ of the forest land at the scale of whole stands (Forest Stewardship Council 2010). 


\subsection{Study species}

Diacanthous undulatus is a representative of the species-rich insect community dwelling under bark of dead wood, which is negatively affected by reductions in the amount of dead wood due to forestry (Jonsell et al. 1998). It was previously classified as near threatened (NT) on the Swedish red list (Gärdenfors 2010), but its status has recently been changed to least concern (LC) (Swedish Species Information Centre 2015). It is a predatory beetle occurring in dead wood from both coniferous and deciduous trees (Nilsson and Baranowski 1996) in unmanaged forest, old managed forest, and clear-cuts (Schroeder et al. 2007). In managed forest landscapes, this species seems to occur as habitat-tracking metapopulations, since (i) local populations can go extinct both due to stochastic events in small populations and habitat patches becoming unsuitable (during a rotation, a managed forest stand will have periods of both suitability and unsuitability for the species), (ii) the probability of occurrence increases with the time since the stand became suitable, which suggests a dispersal limitation, and (iii) predictions from a habitat-tracking metapopulation model were significantly correlated with the current occurrence patterns (Schroeder et al. 2007).

The information about current populations of $D$. undulatus used in this study was drawn from a presence/absence dataset obtained from a field study carried out during 2001-2003, described in detail by Schroeder et al. (2007). A stratified sampling design was applied, which means that data was collected from randomly selected forest stands of the following categories: clear-cuts (20 stands), old managed forest (28 stands), set-asides (10 stands) and nature reserves (10 stands), while beetle data were impossible to collect from young managed forests simply because there was too little dead wood with bark (and hence breeding substrate) to sample. Briefly, the presence/absence of $D$. undulatus larvae was assessed by peeling bark from dead wood objects (diameter $>10 \mathrm{~cm}$, both downed and standing and belonging to different tree species), sieving the material, and extracting larvae (if present) in Tullgren funnels. Use of this method ensures that any detected members of the species must have originated from reproduction in the stand. If available, $1 \mathrm{~m}^{2}$ of bark from 10 dead wood objects were sampled per stand, otherwise as many as possible. We assessed presence/absence at one time for each stand; the species was present in 15 stands out of 68 . 


\subsection{Modelling stand development and optimizing stand management}

We modelled forest development and management using tree growth, regeneration and mortality functions implemented in the forest planning tool Heureka PlanWise (Wikström et al. 2011), where the simulation and optimization settings can be modified to represent a multitude of different goals in forestry. Here we optimized NPV for each forest stand by comparing the outcomes for a range of management programs, each consisting of a sequence of treatments (planting, pre-commercial thinning, thinning and clearcutting, or no treatment) applied over 200 years divided into five-year time periods, and choosing the management programs for each stand that would maximize its NPV. With no requirement for landscape-scale sustainable yield or additional constraints applied, this represents the situation where forest owners maximize solely the profit for forest management.

The current forest conditions in the study landscape (average values for tree age, basal area, stem density, site index, and tree species distributions) were obtained from stand-level databases maintained by the industrial landowners. In all cases, even-aged management was simulated, as this is the prevailing management practice in the area. We assumed in all management programs that $5 \%$ of each stand would be retained at clearcutting to meet FSC certification requirements for tree retention (Forest Stewardship Council 2010). The regeneration settings for the current and subsequent generations of a stand were the same, since the dominating tree species generally depends on the soil characteristics.

The harvest revenues from timber and pulpwood were calculated using theoretical bucking of trees (Näsberg 1985) and stumpage prices drawn from the prevailing industry price list for the region (Mellanskog 2013). Drawing on the classical Faustmann model (Faustmann 1849), the NPV for a given management program was computed as the sum of discounted net revenues for an infinite time horizon (approximated by assuming that the same management regime would be repeated in perpetuity after two rotations), with a discount rate of $3 \%$, which is the commonly used rate in the region.

Thinning guides were used to determine timing and intensity of thinning for a baseline management program, and the timing was subsequently varied by the Heureka system when generating management program alternatives. Clearcutting age was also 
allowed to vary. To make it possible to increase the length of the rotations (see section 2.5), we related the optimal clearcutting age to the minimum clearcutting age according to the Swedish Forestry Act. This minimum clearcutting age is set as a function of site index and main tree species (Anon. 1994), and varies for most stands addressed in this study between 60 and 90 years. We found that, on average, the optimal clearcutting age was 19.9 years higher than that. Therefore, when the rotations were not prolonged, for all stands the clearcutting age was set to the minimum cleatcutting age +20 years.

\subsection{Modelling species persistence}

The findings of Schroeder et al. (2007) based on snapshot data alone (see above) suggest that $D$. undulatus occurs in a habitat-tracking metapopulation, with each forest stand constituting a habitat patch. Studies of other saproxylic beetles based on repeated surveys have confirmed that saproxylic beetles are indeed colonizing and going extinct from forest stands, where successional habitat changes is an important factor (Ranius et al. 2014; Rubene et al. 2014). Thus, we based our modelling on the assumption that in each year, colonizations may occur in suitable forest stands where the species is absent and extinctions from stands where the species is present. Here, local colonizations and extinctions of the focal species (i.e. the metapopulation dynamics) were predicted using equations with parameter estimates obtained from Monte Carlo simulations using presence/absence data from the study area as described in the Appendix A. The equations are based on metapopulation theory, assuming that the patch-level rate of colonization is related with the connectivity to dispersal sources and the rate of local extinction with the patch-level amount of habitat (Hanski 1994). The assumptions behind the equations are similar to the incidence function model (Hanski 1994), but we assumed that our system is not in an equilibrium since the amount of habitat has recently decreased in the study landscape (Schroeder et al. 2007). Since both colonisations and local extinctions are stochastic events, we expect discrepancies between field data and model predictions regarding individual stands. However, the parameterized model predicted current presence/absence patterns per stand better than a null model (with 50 replicates, presence was predicted for $39 \%$ of those occupied, and for $21 \%$ of those unoccupied, while randomly 25\% would have been occupied in both categories; $\mathrm{p}<0.001, \chi^{2}$ test). 
We obtained information about the future habitat quality of forest stands from the predicted future forest conditions. The productive forest stands in the study landscape were divided into three types: $i$ ) unmanaged forests, which are assumed to be always suitable for D. undulatus; ii) stands managed with clearcutting, which are suitable for D. undulatus when they are $<10$ years and $\geq 60$ years old and unsuitable at all other ages; and iii) stands planted with the nonnative tree species lodgepole pine (Pinus contorta), which are never suitable for $D$. undulatus. We modelled habitat quality in suitable stands as described in Appendix B, assuming that it increases with increases in abundance of the species' substrate (dead wood with bark) and reductions in altitude (Schroeder et al. 2007).

The size of the simulated area was adjusted to $50 \mathrm{~km}^{2}$ to obtain extinction risks allowing comparisons between scenarios; in considerably smaller or larger areas the extinction risks over 200 years are always close to 100\% and 0\%, respectively, in line with other metapopulation studies showing a strong relationship between size of the habitat network and extinction risks (Léon-Cortés et al. 2003). This means that with an inappropriate size of the simulated area, between-scenario differences would be masked. We assumed that rates of immigration of individuals from adjacent landscapes were equal to the emigration rates. To ensure this equivalence in the simulations, we wrapped around the edges of the landscape so stands situated at the left and upper margins were bounded to those at the right and lower margins, respectively, as if they were located on a donutshaped surface.

\subsection{Forest management scenarios}

First, we applied a "No conservation effort” scenario, where no forest land was set aside at the scale of whole stands and the rotations were not prolonged. Second, we tested a scenario close to the current management regime. In this scenario, 5\% of the forest land was set aside, the oldest stands being selected as set-asides. The cost of this scenario, in terms of the loss of NVP relative to the NPV in the "No conservation efforts" scenario was used to set the budget for conservation. This cost equals the sum of the NPV of the setasides, which in our analyzed $50 \mathrm{~km}^{2}$ area was 9.14 million SEK. We compared this with other scenarios where conservation efforts were conducted with the same budget constraint. The fixed budget set for the long simulation period is not that meaningful from 
a practical viewpoint, but it enables an assessment of the cost effectiveness of the scenarios. Initially, we tested scenarios where a varying proportion of the budget was allocated for setting aside the youngest stands. In these scenarios, 100, 80, 60, 40, 20 and $0 \%$ of the budget was assigned to setting aside old stands and the rest to setting aside young stands. Finally, we tested scenarios with rotations prolonged by 20 and 40 years, while we found it impossible to use the whole budget if they were prolonged by only 5 or 10 years. The mean rotation period with no prolongation was 88 years (range: 70 to 145 years). The prolongation was obtained by calculating the optimal harvest age for each stand as the minimum legal clear-cutting age plus 20 years (which was the average difference in our scenario with no conservation effort). For instance, to obtain a prolongation of 40 years, 60 years were added to the minimum legal clear-cutting age but we did not change anything else in the management regime. In each case the prolongation was applied to as many randomly selected stands as possible under the budget constraint. Below, we only present the outcome from the prolongation that resulted in the lowest extinction risk (i.e. 20 years).

All scenarios implicitly assumed that for each stand a management regime (counting "No management" as one regime) is defined at the beginning and maintained during the whole simulation period (200 years). When selecting the youngest and oldest stands for setting aside, stands with the lowest and highest initial ages, respectively, were selected until the maximum cost allowed by the budget was reached. The stands with prolonged rotations were selected randomly, regardless of their initial age.

We made a set of 500 simulation replicates for each scenario. The variation in predicted extinction risks among sets of replicates generally varies with the extinction risk, with a maximum at a 50\% extinction risk. For that extinction risk level, the $95 \% \mathrm{CI}$ is $\pm 4.4 \%$ (unpubl. data). Thus, all presented differences in extinction risk among scenarios exceeding $4.4 \%$ were statistically significant. Predictions of habitat availability, set-aside area, and harvested volumes were made with equations which do not involve stochasticity, and therefore they have no variation in the output data. 


\section{Results}

All tested conservation efforts - setting aside young or old forest, or prolonging rotations had clearly positive effects on species persistence in comparison to conducting no conservation efforts (Fig. 1). During the first century, setting aside mainly old stands was the most efficient strategy to decrease the extinction risk. However, during the second century, the extinction risk was much lower when at least some young forest was set aside (Fig. 1), because habitat availability was considerably higher during that period when setting aside young forest stands instead of old ones (Fig. 2a). Over the whole period, the extinction risk was lowest when about $80 \%$ of the budget was spent on setting aside the oldest stands and the remaining $20 \%$ on setting aside the youngest ones (Fig. 1).

When the rotation period was prolonged by 20 years throughout the 200 -year period under the set budget constraint, 79\% of the forest area was subjected to prolonged rotations. During the first century this resulted in similar extinction risks to those obtained in the best set-aside scenarios, but during the second century the extinction risk was higher than for any scenario involving set-asides (Fig. 1).

Because the youngest stands were much cheaper to set aside than the oldest, with a constant conservation budget the total set-aside area increased with the proportion of young forest (Fig. 3). Thus, the harvested volume decreased more when young forest was set aside than when old forest was set aside. This difference was slightly more pronounced during the second century (Fig. 4). Prolonged rotations had a clearly negative effect on the harvested volume only during the first century (Fig. 4).

\section{Discussion}

\subsection{Young vs. old set asides}

Traditionally, old stands have been prioritized when selecting set-asides for biodiversity conservation (Gustafsson and Perhans 2010), mainly because they harbor structures and species that are rare in forest landscapes dominated by managed forest. The present study shows, in accordance with previous findings (Lundström et al. 2016; Mazziotta et al. 2016), that it may be favorable to set aside some proportion of young stands too. This is due to the fact that they are cheaper to protect, meaning that larger areas can be set aside with a given conservation budget. However, it is only when combining with a large 
proportion of old stands, setting aside young stands can be favourable (Fig. 1). This is because species dependent on structures that mainly occur in old forest will experience a long delay before setting aside young forest results in increased habitat amounts. This is important to consider because the total amount of habitat was a key factor affecting differences in extinction risks over time and between landscape scenarios in the present study. Bottlenecks in habitat availability can therefore threaten long-term population viability. Such bottlenecks occurred in the prediction for our study area (i.e. the habitat availability was lower at 0-50 years than both earlier and later; Fig. 2a), and have been observed in other managed forest landscapes in Sweden (Roberge et al. 2015). We found that extinction risk was most strongly reduced when about $20 \%$ of the budget was spent on young set-asides and the rest on old ones. These proportions combine the advantages of including very young forests that are cheapest to set aside and old forests which limit bottleneck effects. The optimal proportions probably depend on the target species and landscapes (cf. Mazziotta et al. 2016). However, we conclude that with a long planning horizon, allocating a proportion of conservation resources for setting aside young stands may be advantageous, as long as old stands are also set aside.

Given a certain conservation budget, setting aside a larger area of young forest rather than old forest implies a decrease in the total production forest area and hence in the future volumes of timber potentially harvested in the forest landscape (Fig. 3-4). The estimated cost of setting aside young forest is comparatively low, despite the consequent reductions in future timber harvest, because the income loss is discounted and in the far future. The higher the assumed discount rate, the more favorable is the net income in the near future relative to later incomes. Therefore, the discount rate may have a large influence when comparing the cost-effectiveness of conservation scenarios (Mazziotta et al. 2016). This rate is highly dependent on the decision-maker's preferences and may vary over time. Therefore, a whole range of assumptions about discount rates is possible, including also time-declining discount rates (Weitzman 2010). There is no consensus regarding the correct value of discount rate (e.g. Hepburn and Kondouri 2007) but the $3 \%$ interest rate used in this study is typical for forest management calculations in Sweden, reflecting moderate risk and profit expectations (e.g. Brealey et al. 2012). 
Both young and old forest may harbor structures that are important for biodiversity. Our study species occurs in old forest and also in dead wood on clear-cuts for a few years following cutting (Schroeder et al. 2007). Other species may strongly prefer either old forest or clear-cuts, since these habitats offer strongly diverging environmental conditions (Kaila et al. 1997). For species dependent on old-growth forest conditions, setting aside old forests is an adequate conservation measure, but the present study suggests that combining that with setting aside young forest could also be an efficient measure in the long term. However, at least some forest species (although not our study species) seem to require habitat continuity (Siitonen and Saaristo 2000) and for them it may be necessary to retain older forests which have never been clear-cut. Habitats of high conservation value that occur after clearcutting and forest fires may be legacies from the previous stand, such as dead wood (Kaila et al. 1997; Rubene et al. 2014) or created by the disturbances, such as flower-rich sites (Rubene et al. 2015) and artificially created high stumps (Djupström et al. 2012). Many of these structures and associated species will be lost during the succession, regardless of whether the stand is set aside or not. Therefore, measures other than setting aside stands may be needed to sustain these species, such as applying more conservationoriented practices during forestry operations, maintaining more gaps, and delaying the densification of young forest (Rubene et al. 2014). In conclusion, the main value of setting aside old forests is that it maintains current conservation values, while the main rationale of permanently setting aside young forests is to secure high conservation values in the future, rather than to maintain present values.

\subsection{Prolongation of the rotation periods}

Landscape-level extinction risks were lower when rotations were prolonged by 20 years than in the scenario with no conservation efforts. This was at least partly due to increases in total habitat availability at the landscape scale (cf. Mönkkönen et al. 2014), but prolonging rotations may also extend the period when stands provide suitable habitats, and thus increase probabilities of their colonization (cf. Keymer et al. 2000). However, the best scenario for prolonging rotations still resulted in a higher extinction risk than the best scenario of set-asides. Thus, our results suggest that prolonging rotations is a less efficient measure than setting aside stands in the long term. This is a likely outcome especially for 
species with low colonization ability (such as some epiphytes; Löbel et al. 2006), because such species are favored by the occurrence of sites where they can persist over long periods but cannot readily recolonize managed forest stands, which change over time (Ranius and Roberge 2011). However, for stronger colonizers site persistence has weaker effects, since they are better at tracking the changing habitat in managed forests. Prolonging the rotation had a clear negative effect on the landscape-level harvested volumes only during the first century, mainly because the harvest occasions become delayed. Thus, the main cost of prolonging the rotation is delaying income from forest harvesting, which decreases the value of income due to discounting. Thus, prolonged rotations caused quite moderate costs per unit forest area (on average 9 \% decrease in NPV). For that reason, prolonging rotations may still be an attractive option for forest owners. For instance, some may prefer to postpone harvesting, to keep possibilities open and decide later whether to set aside a stand or cut it. This feature has been utilized in forest conservation programs based on temporal contracts agreed between private landowners and the government (e.g. Juutinen et al. 2008). There are also other advantages associated with prolonged rotations, such as generally positive effects on e.g. aesthetics, water quality, soil nutrients, and berry production (Roberge et al. 2016). Nevertheless, given the low long-term effect of prolonged rotations observed in this study, and its limited value for species with low dispersal ability, prolongation of rotations should be combined with setting aside forests in the same landscape if the aim is to conserve wider biodiversity.

\subsection{Spatial and temporal scales}

The outcome from this kind of analyses is highly scale-dependent, in terms of both economic returns and species persistence. If the scenarios are applied at the spatial scale considered in our analyses $\left(50 \mathrm{~km}^{2}\right)$ market-level effects do not have to be taken into account (cf. Nalle et al. 2014), and thus, timber prices was assumed to be the same in all scenarios. However, if applied over larger regions the scenarios would have different effects on future industrial timber supplies, thus potentially affecting forest owners and forest industry through changed prices (Johansson and Löfgren 1985). Predicted levels of extinction risks are also inversely dependent on the size of the simulated landscape, since a larger landscape size means that there are more local populations with a partly independent 
dynamics (cf. Léon-Cortés et al. 2003). Therefore, although useful for comparing relative effects of various scenarios, our analyses provide no indications of extinction risks of $D$. undulatus at national or other larger scales.

The outcome is also highly dependent on the considered time horizon. Some uncertainties obviously increase with the time scale of the predictions, since over a longer time the conditions potentially can drift away further from the current conditions. This is the case for, for instance, societal values, economic evaluations, and climatic conditions. On the other hand, less change is expected regarding the biology of species or the relative amount of harvested volume given different scenarios. A time horizon of up to 100 years is commonly used for long-term forest planning (e.g. Öhman and Eriksson 2010). However, we found that the outcome, in terms of relative extinction risks, may be substantially different if it is extended with another 100 years. Two reasons for the differences in risks between the first and second centuries are that habitat amounts vary over time (Fig. 2), and populations of the focal organisms were larger at the starting point than after 100 years. In this study, reductions in extinction risks were not discounted, i.e. we assumed that the society's values of ecological benefits would remain constant throughout the study period. There is no consensus regarding methodology for defining likely interest rates regarding environmental benefits that may accrue far in the future (e.g. Nordhaus 2007; Weitzman 2010). However, it is widely assumed that discount rates for environmental benefits from nature conservation should be well below rates applied for economic benefits (Gollier 2010; Kula and Evans 2011), which is consistent with our analyses. This is because ecological and biodiversity values are at least partially non-substitutable by economic growth or consumption. Nature conservation is intended to ensure intergenerational equity and provide an adequate basis for long-term persistence of biodiversity, which suggests that biodiversity will be equally or even more valuable in the future than at present.

\section{Conclusions}

Since old stands are generally expensive to protect, given the financial resources commonly available for conservation, set-aside areas will likely remain small. Thus losses of timber harvest are also expected to remain limited when prioritizing old stands for protection. Much more extensive areas of younger stands can be set aside within given 
budgetary constraints, because they are cheaper. In the long run this would increase amounts of habitats that are scarce in production forests, and decrease potential future timber harvests. Prolonging rotations reduced extinction risks of our focal organism, but was less cost-efficient than setting aside forest. Thus, the most cost-efficient strategy to preserve the study species over 200 years was to set aside a mixture of old and young forest. However, setting aside young stands rather than prolonging rotations or setting aside old stands delays both landscape-level costs (losses of harvested volumes) and benefits (reductions in extinction risks), so the optimal strategy depends on the assumed societal values and hence discount rates.

Because model parameters are based on scant data, and considering that we only studied a single species in a certain landscape, the outcome should not be generalized incautiously, but considered an example of a possible outcome. However, our results may well apply to numerous forest species associated with large-diameter dead wood. This substrate harbors a species-rich community of conservation concern, since the amount of large-diameter dead wood has severely declined in regions with intensive forest management (Jonsson et al. 2005). Moreover, our study area is largely representative of managed boreal landscapes of northern Europe, where management has been intensive in recent decades. Hence, our results are likely relevant to numerous landscapes facing similar conservation challenges.

\section{Acknowledgements}

Ljusk Ola Eriksson helped with Heureka calculations. This study was supported by the research program Future Forests and the Swedish Research Council for Environment, Agricultural Sciences and Spatial Planning (Formas) [grant no. 215-2008-539 to TR], the Academy of Finland (project no. 275329 to MM), the Kone Foundation (to MM), and the Kempe Foundation (no. SMK-1339 to JMR).

\section{Role of the funding sources}

Those who have given financial support have not played any role when we made decisions about the performance of this project. 


\section{References}

Anon. 1994. Skogsvårdslagen. Handbok. Skogsstyrelsen, Jönköping [In Swedish].

Anon. 2016. Sweden's environmental objectives - an introduction. Swedish Environmental Protection Agency, Stockholm.

Brealey, R., Myers, S., Allen, F. 2013. Principles of corporate finance. McGraw Hill, New York.

Djupström, L.B., Weslien, J., ten Hoopen, J., Schroeder, L.M. 2012. Restoration of habitats for a threatened saproxylic beetle species in a boreal landscape by retaining dead wood on clearcuts. Biological Conservation 155, 44-49.

Ekbom, B., Schroeder, L.M., Larsson, S. 2006. Stand specific occurrence of coarse woody debris in a managed boreal forest landscape in central Sweden. Forest Ecology and Management 221, 2-12.

Faustmann, M. 1849. Berechnung des Wertes welchen Waldboden sowie noch nicht haubare Holzbestände für die Waldwirtschaft besitzen. Allgemeine Forst- und Jagd-Zeitung, vol. 15. Republished in 1995 with the title "Calculation of the value which forest land and immature stands possess for forestry”. Journal of Forest Economics 1, 7-44.

Forest Stewardship Council. 2010. Swedish FSC standard for forest certification including SLIMF indicators. FSC Sweden, Uppsala.

Fries, C., Bergquist, J., Wikström, P. 2015. Lägsta ålder för föryngringsavverkning (LÅF) - en analys av följder av att sänka åldrarna i norra Sverige till samma nivå som södra Sverige. Rapport 6/2015 Skogsstyrelsen, Jönköping [In Swedish].

Gärdenfors, U. 2010. The 2010 Red List of Swedish species. Swedish Species Information Centre, Uppsala.

Gollier, C. 2010. Ecological discounting. Journal of Economic Theory 145, 812-829.

Gustafsson, L., Perhans, K. 2010. Biodiversity conservation in Swedish forests: ways forward for a 30-year-old multi-scaled approach. Ambio 39, 546-554.

Hanski, I. 1994. A practical model of metapopulation dynamics. Journal of Animal Ecology 63, 151-162.

Hepburn, C., Kondouri, P. 2007. Recent advances in discounting: Implications for forest economics. Journal of Forest Economics 13, 169-189.

Johansson, P.-O., Löfgren, K.-G. 1985. The economics of forestry and natural resources. Basil Blackwell Ltd, UK. pp 292.

Jonsell, M., Weslien, J., Ehnström, B. 1998. Substrate requirements of red-listed saproxylic invertebrates in Sweden. Biodiversity and Conservation 7, 749-764.

Jonsson, B.G., Kruys, N., Ranius, T. 2005. Ecology of species living on dead wood - lessons for dead wood management. Silva Finnica 39, 289-309.

Jonsson, M., Ranius, T., Ekvall, H., Bostedt, G., Dahlberg, A., Ehnström, B., Nordén, B., Stokland, J.N. 2006. Cost-effectiveness of silvicultural measures to increase substrate availability for red-listed wood-living organisms in Norway spruce forests. Biological Conservation 127, 443462.

Juutinen, A., Mäntymaa, E., Mönkkönen, M., Svento, R. 2008. Voluntary agreements in protecting privately owned forests in Finland - To buy or to lease? Forest Policy and Economics 10, 230-239.

Juutinen, A., Ollikainen, M., Mönkkönen, M., Reunanen, P, Tikkanen, O.-P., Kouki, J. 2014. Optimal contract length for biodiversity conservation under conservation budget constraint. Forest Policy and Economics 47, 14-24.

Kaila, L., Martikainen, P., Punttila, P. 1997. Dead trees left in clear-cuts benefit saproxylic Coleoptera adapted to natural disturbances in boreal forest. Biodiversity and Conservation 6, $1-18$.

Keymer, J.E., Marquet, P.A., Velasco-Hernández, J.X., Levin, S.A. 2000. Extinction thresholds and metapopulation persistence in dynamic landscapes. American Naturalist 156, 478-494. 
Kula, E., Evans, D. 2011. Dual discounting in cost-benefit analysis for environmental impacts. Environmental Impact Assessment Review 31, 180-186.

Lassauce, A., Larrieu, L., Paillet, Y., Lieutier, F., Bouget, C. 2013. The effects of forest age on saproxylic beetle biodiversity: Implications of shortened and extended rotation lengths in a French oak high forest. Insect Conservation and Diversity 6, 396-410.

León-Cortés, J.L., Lennon, J.J., Thomas, C.D. 2003. Ecological dynamics of extinct species in empty habitat networks. 1 . The role of habitat pattern and quantity, stochasticity and dispersal. Oikos 102: 449-464.

Lindenmayer, D.B., Franklin, J.F. 2002. Conserving forest biodiversity. Island Press: a comprehensive multiscaled approach. Washington D.C.

Löbel, S., Snäll, T., Rydin, H. 2006. Metapopulation processes in epiphytes inferred from patterns of regional distribution and local abundance in fragmented forest landscapes. Journal of Ecology 94, 856-868.

Lundström, J., Öhman, K., Rönnqvist, M., Gustafsson, L. 2016. Considering future potential regarding structural diversity in selection of forest reserves. PloS One 11, e0148960.

Mazziotta, A., Pouzols, F.M., Mönkkönen, M., Kotiaho, J.S., Strandman, H., Moilanen, A. 2016. Optimal conservation resource allocation under variable economic and ecological time discounting rates in boreal forest. Journal of Environmental Management 180, 366-374.

Mellanskog. 2013. Virkespriser Nordöstra Hälsingland. Mellanskog Skogsägarna, Uppsala, Sweden [In Swedish]. Available from https://www.mellanskog.se/Vara-tjanster/Virkespriser/ (accessed February 2014).

Mönkkönen, M., Juutinen, A., Mazziotta, A., Miettinen, K., Podkopaev, D., Reunanen, P., Salminen, H., Tikkanen, O.-P. 2014. Spatially dynamic forest management to sustain biodiversity and economic returns. Journal of Environmental Management 134, 80-89.

Nalle, D., Montgomery, A.C., Arthur, J., Polasky, S., Schumaker, N. 2004. Modelling joint production of wildlife and timber. Journal of Environmental Economics and Management 48, 997-1017.

Näsberg, M. 1985. Mathematical programming models for optimal log bucking. Doctoral Dissertation. Dept. of Mathematics, Linköping University.

Nilsson, S.G., Baranowski, R. 1996. Changes in the Swedish distribution of click beetles (Elateridae) occurring in the boreal forest. Entomologisk Tidskrift 117, 87-101.

Nordhaus, W. 2007. A review of the Stern Review on the Economics of climate change. Journal of Economic Literature XLV, 686-702.

Öckinger, E., Nilsson, S.G. 2010. Local population extinction and vitality of an epiphytic lichen in fragmented old-growth forest. Ecology 91, 2100-2109.

Öhman, K., Eriksson, L.O. 2010. Aggregating harvest activities in long term forest planning by minimizing harvest area perimeters. Silva Fennica 44, 77-89.

Ranius, T., Roberge, J.-M. 2011. Effects of intensified forestry on the landscape-scale extinction risk of dead wood dependent species. Biodiversity and Conservation 20, 2867-2882.

Ranius, T., Bohman, P., Hedgren, O., Wikars, L.-O., Caruso, A. 2014a. Metapopulation dynamics of a beetle species confined to burned forest sites in a managed forest region. Ecography 37, 797-804.

Roberge, J.M., Lämås, T., Lundmark, T., Ranius, T., Felton, A., Nordin, A. 2015. Relative contributions of set-asides and tree retention to the long-term availability of key forest biodiversity structures at the landscape scale. Journal of Environmental Management 154, 284-292.

Roberge, J.M., Laudon, H., Björkman, C., Ranius, T., Sandström, C., Felton, A., Sténs, A., Nordin, A., Granström, A., Widemo, F., Bergh, J., Sonesson, J., Stenlid, J., Lundmark, T. 2016. Socio-ecological implications of modifying rotation lengths in forestry. Ambio 45(Suppl. 2), S109-S123. 
Rubene, D., Wikars, L.O., Ranius, T. 2014. Importance of high quality early-successional habitats in managed forest landscapes to rare beetle species. Biodiversity and Conservation 23, 449466.

Rubene, D., Schroeder, L.M., Ranius, T. 2015. Diversity patterns of wild bees and wasps in managed boreal forests: Effects of spatial structure, local habitat and surrounding landscape. Biological Conservation 184, 201-208.

Schroeder, L.M., Ranius, T., Ekbom, B., Larsson, S. 2007. Spatial occurrence of a habitat-tracking saproxylic beetle inhabiting a managed forest landscape. Ecological Applications 17, 900909.

Secretatiat of the Convention on Biological Diversity. 2010. Global Biodiversity Outlook 3, pp. 94. Secretatiat of the Convention on Biological Diversity, Montreal, QC.

Siitonen, J., Saaristo, L. 2000. Habitat requirements and conservation of Pytho kolwensis, a beetle species of old-growth boreal forest. Biological Conservation 94, 211-220.

Swedish Species Information Centre. 2015. Rödlistade arter i Sverige 2015 [Redlisted species in Sweden 2015] Swedish Species Information Centre, Uppsala [In Swedish, English summary].

Virolainen, K.M., Ahlroth, P., Hyvärinen, E., Korkeamäki, E., Mattila, J., Päivinen, J., Rintala, T., Suomi, T., Suhonen, J. 2000. Hot spots indicator taxa, complementarity and optimal networks of taiga. Proceedings of the Royal Society Series B: Biological Sciences 267, 11431147

Weitzman, M. 2010. Risk-adjusted gamma discounting. Journal of Environmental Economics and Management 60, 1-13.

Wikström, P., Edenius, L., Elfving, B., Eriksson, L.O., Lämås, T., Sonesson, J., Öhman, K., Wallerman, J., Waller, C., Klintebäck, F. 2011. The Heureka forestry decision support system: An overview. Mathematical and Computational Forestry and Natural-Resource Sciences 3, 87-95. 


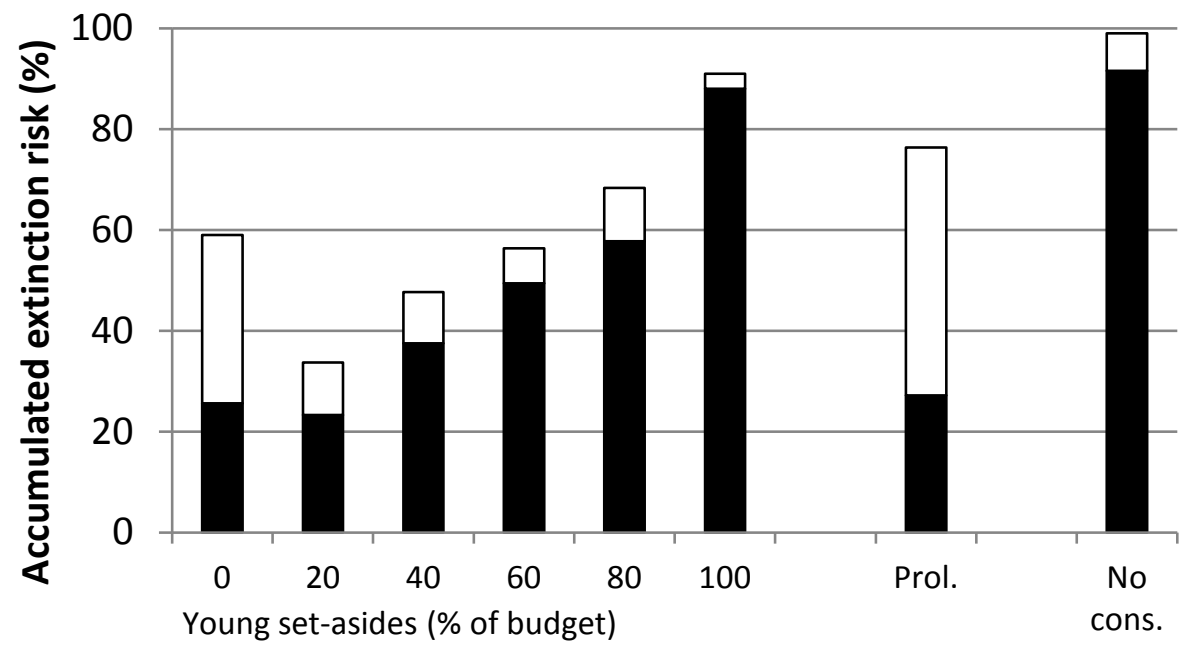

Fig. 1. Predicted accumulated extinction risk for a beetle, Diacanthous undulatus, in a 50 $\mathrm{km}^{2}$ managed forest landscape during a 200-year period, under seven scenarios with the same conservation budget and one scenario with no conservation efforts. Black = during the first century from now (0-100 yrs), white $=$ during the second century (100-200 yrs). In the first six scenarios, forest stands are selected for setting aside based on their age; the numbers $(0,20, \ldots, 100)$ indicate the percentage of the budget allocated to setting aside the youngest stands, while the rest is spent on the oldest stands. "Prol" is a scenario with the same conservation budget in which the rotation period of randomly chosen stands is prolonged by 20 years. In all scenarios, some trees were retained in stands at clearcutting in accordance with FSC rules. 
a)

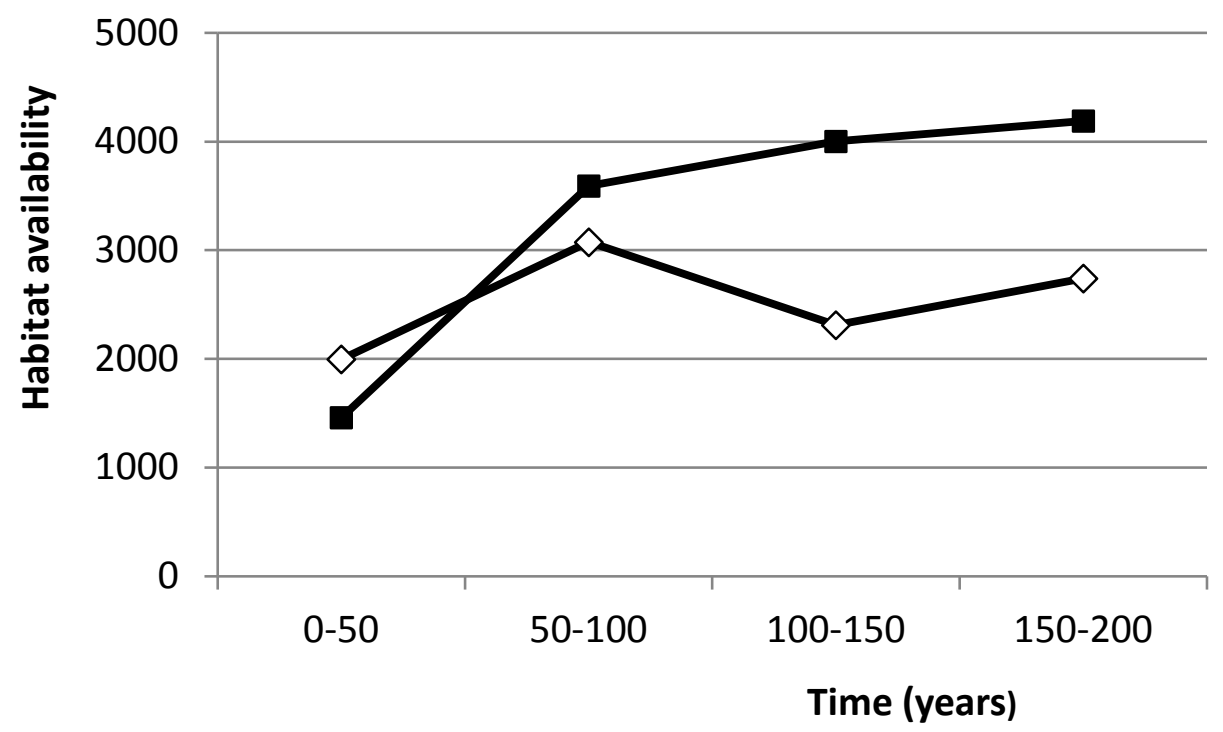

b)

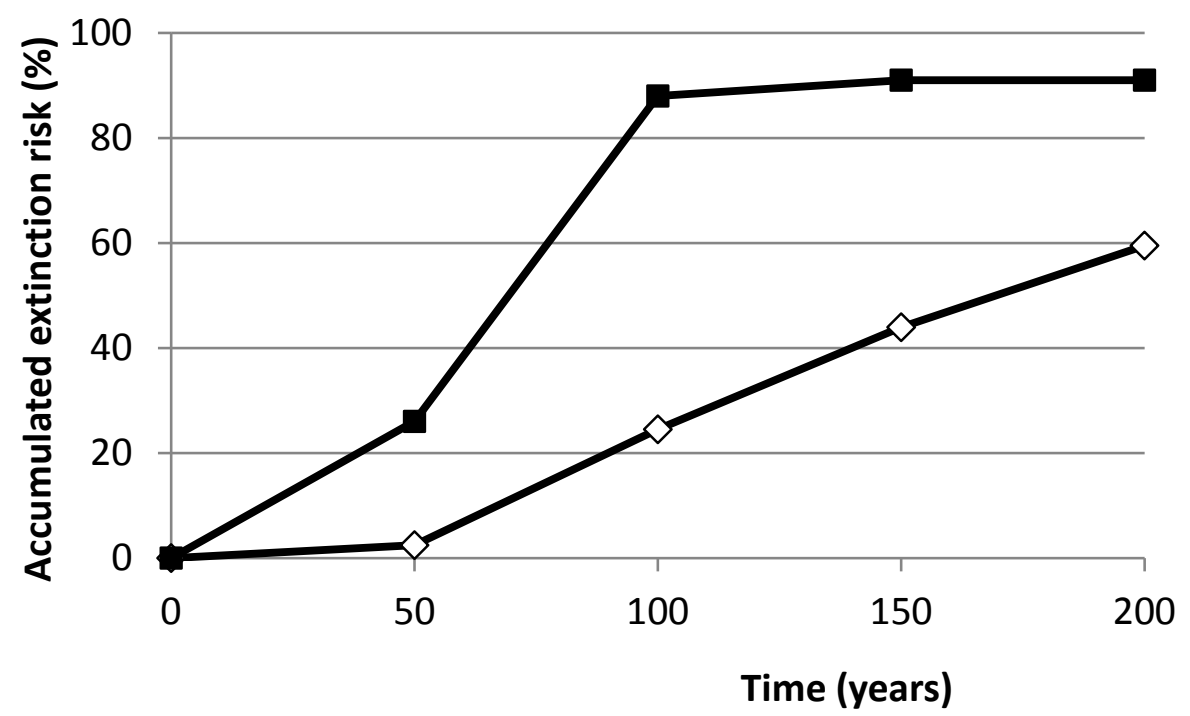

Fig. 2. Predicted habitat availability (a) and accumulated extinction risk (b) for the beetle Diacanthous undulatus in a $50 \mathrm{~km}^{2}$ managed forest landscape, in scenarios where only the youngest (black squares) or only oldest (open diamonds) stands are set aside, with the same conservation constraints. Predicted habitat availability refers to mean amounts, over 50-year periods, measured as described in the Appenedix A. 


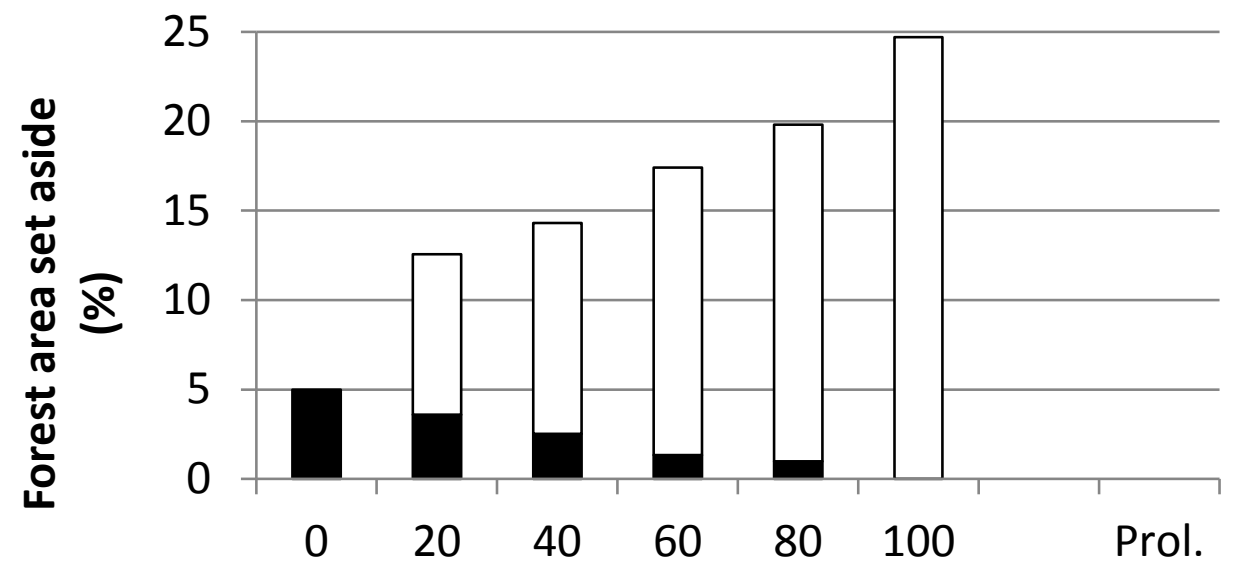

Fig. 3. Areas (\%) of forest set aside when percentages of a given conservation budget from 0 to 100 (x axis) are allocated to setting aside the youngest stands and the rest to setting aside the oldest stands. Filled part of the bars = old forest. Open parts of the bars = young forest. No forest is set aside if the same budget is used to prolong rotations (Prol.). In the Prol. scenario the rotation period of randomly chosen stands covering $79 \%$ of the forest area is prolonged by 20 years.

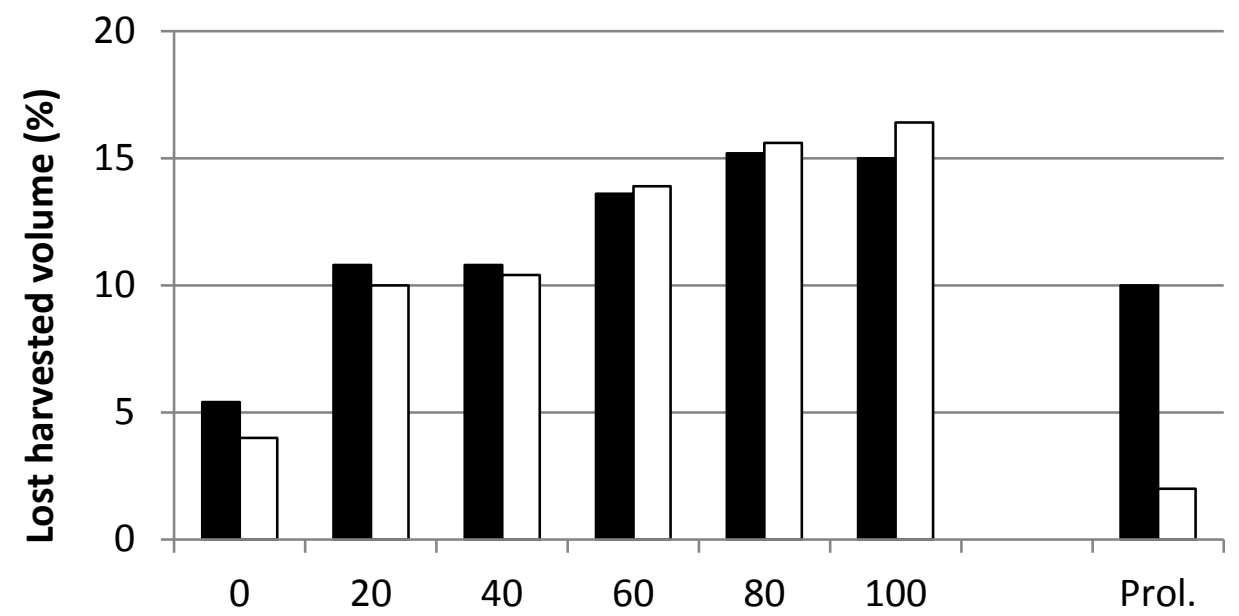

Fig. 4. Percentage of the harvest volume lost, relative to the volume in a scenario with no retained stands and no prolonged rotations. Filled bars = during the first century from now . Open bars = during the second century. In the first six scenarios forest stands are selected for setting aside based on their age; the numbers $(0,20, \ldots, 100)$ indicate the percentage of the budget allocated to setting aside the youngest stands, while the rest is spent on the oldest stands. "Prol" is a scenario with the same conservation budget in which the rotation period of randomly chosen stands is prolonged by 20 years. 


\section{Appendix A}

\section{Fitting a metapopulation model}

We fitted a metapopulation model using stand-level presence/absence data and Monte Carlo simulations. We assumed a dynamic landscape, as described in the Methods section and Appendix B, and that colonizations and extinctions are not currently in equilibrium in the study landscape, because the landscape-level amount of habitat has decreased in recent decades. In the Monte Carlo simulations, we started with a wide range of values for each of the seven unknown parameters in the model (Table A.1). These ranges are collectively referred to as a parameter space. By repeated simulations, the parameter space was successively narrowed in the following way. In each simulation, we ran a set of 1000 replicates with parameter values randomly chosen within the parameter space. Each replicate resulted in a prediction of presence/absence for every forest stand in the study landscape, which was compared with field data. When a replicate resulted in an occupancy of $12-32 \%$ (field data: $22 \%$ ) and a significantly $\left(\mathrm{p}<0.05, \chi^{2}\right)$ positive correlation between predicted and observed presence/absence, the combination of parameter values was identified as a "probable combination". However, for the first 10 simulations, we only considered the occupancy, since significant correlations in presence/absence data were very rare. For each set of 1,000 replicates, we analyzed the effect of one parameter at a time by dividing the parameter value interval into four equally large sections. We identified one or two parameters that had the biggest difference in proportion of probable combinations between sections. Then we decreased the parameter space by $50 \%$, by delimiting the interval for the parameters with the biggest difference so only the sections with the highest proportion of probable combinations remained. When this had been done 50 times, there were only small differences between the parameter value interval sections. The mean value in each parameter interval in the final parameter space was used as a parameter value in the simulation of future development (Table A.1). Two variables, $\alpha$ and $u$, had strong effects on the occupancy in opposite directions. To increase the probability of obtaining "probable combinations", we substituted the $u$ parameter by a function with two parameters, $a$ and $b$ :

$\mathrm{u}=\mathrm{a}-\mathrm{b} \alpha$ eq. (A.1)

The $a$ and $b$ parameters were treated in the same manner as the other parameters, as described above. With this approach, we obtained a parameter combination consistent with field data.

The starting point for each Monte Carlo simulation was 1950 and the output was compared with field data from 50 years later. In the simulations, species occurrences in 1950 were placed randomly among the forest stands. The initial incidence per patch, $I$, was varied between $22 \%$ (= the current occupancy) and 100\%. The probabilities of local colonizations and extinctions were estimated in every stand and every year using eqs. A2- 
A4, similar to those in Hanski (1994). Based on an assumed Allee effect, the colonization probability, $C$, was a sigmoid function of connectivity, $S$ :

Error! Bookmark not defined. $C_{i}=S_{i}^{2} /\left(S_{i}^{2}+y^{2}\right)$

The connectivity of stand $i$ was defined as:

$$
S_{i}=\sqrt{E}_{i} \sum_{j=1}^{n} \exp \left(-\alpha d_{i j}\right) p_{j} A_{j}
$$

where $p=0$ for empty and $p=1$ for occupied stands, $A$ is the patch size according to eq. (B.1), $n$ is the total number of stands in the study, $d_{\mathrm{ij}}$ is the distance between stands $i$ and $j$, and $1 / \alpha$ is the average migration distance. The patch area $E_{\mathrm{i}}$ was included in the equation, as the probability of reaching a habitat patch is likely to be proportional to the square root of its area (Hambäck and Englund 2005). For each year, the probability of extinction $(U)$ in an unsuitable patch is 1 , and the probability of extinction in a suitable patch is

$$
U_{i}=\min \left\{1, u\left(1-C_{i}\right) / A_{i}^{x}\right\}
$$

where $u$ is a parameter governing the extinction risk, $x$ is a parameter governing the effect of patch size, $A$ is the patch size according to eq. $(1)$, and $(1-C)$ represents the rescue effect. When no suitable habitat is available, the larvae of $D$. undulatus do not survive, so we assumed that the local population immediately goes extinct when a habitat patch becomes unsuitable.

\section{Cited literature}

Hambäck, P.A., Englund, G. 2005. Patch area, population density and the scaling of migration rates: the resource concentration hypothesis revisited. Ecology Letters 8, 1057-1065.

Hanski, I. 1994. A practical model of metapopulation dynamics. Journal of Animal Ecology 63, 151-162. 
Table A.1. Parameters in the colonization-extinction modelling. When the parameter values were estimated, we initially tested the whole range of values within the "Interval". "Used value" is the parameter estimate used in the simulations.

\begin{tabular}{|c|c|c|c|}
\hline Name & Variable & Interval & Used value \\
\hline I & Initial incidence & $0.22-1$ & 0.25 \\
\hline $\mathrm{y}$ & $\begin{array}{l}\text { Constant reflecting the probability of a population } \\
\text { establishing in a focal empty patch, given a certain } \\
\text { connectivity with source populations }\end{array}$ & $1-1000$ & 1.16 \\
\hline$\alpha$ & $\begin{array}{l}\text { Dispersal decay (reflecting inverted mean dispersal } \\
\text { distance) }\end{array}$ & $0.0002-0.01^{1}$ & 0.00915 \\
\hline $\mathrm{u}$ & Local extinction risk & $0-1$ & 0.0535 \\
\hline $\mathrm{x}$ & $\begin{array}{l}\text { Constant reflecting how extinction risk varies with } \\
\text { patch area }\end{array}$ & $0.1-1$ & 0.1 \\
\hline & Regional stochasticitity & $0-1$ & 0.303 \\
\hline & Spatial scale of regional stochasticity & $\begin{array}{l}\text { 1, all scales; } 2 \text {, only } \\
\text { largest scale; } 3 \text {, } \\
\text { only smallest scale }\end{array}$ & 2 \\
\hline
\end{tabular}

${ }^{1}$ the limits were based on the spatial scale of the study landscape. 


\section{Appendix B}

\section{Modelling habitat dynamics}

For each forest stand, we predicted the temporal development of habitat quality. Habitat quality, $A$, was assumed to be proportional to the size of inhabiting $D$. undulatus populations and estimated with the following function:

$$
\mathrm{A}=\mathrm{E} \times \mathrm{H} \times \mathrm{D}
$$

where $E$ is the size of the stand (in ha), $H$ an index related to altitude, and $D$ an index reflecting the amount of dead wood (in $\mathrm{m}^{3} / \mathrm{ha}$ ). The value of $H$ was obtained using a logistic regression model, fitted with data on the presence/absence per sieved dead wood item against altitude, $L$ :

$$
H=\exp (6.413-0.026 L) /(1+\exp (6.413-0.026 L))
$$

The dead wood index, $D$, was estimated by the following equation:

$$
\mathrm{D}=\mathrm{F} \times \mathrm{T} \times \mathrm{P}
$$

where $F$ is a forestry factor, $T$ is a tree species factor, and $P$ is a stand productivity factor. We assumed that before 1950, $F=1$ for all stands. Large-scale clearcutting forestry started in 1950, and we assumed after that $F=0$ for all forests $<60$ years old, while for older forests $F=1$. Since the late 1990s, the forestry has been FSC-certified, so more dead wood has been retained during forestry operations. Thus, we assume that after $1998, F=1$ during the first 10 years after clearcutting. These assumptions are consistent with observed amounts of dead wood in the study landscape (Ekbom et al. 2006) and results from simulations of dead wood dynamics (Ranius et al. 2003). After a stand is set aside, $F$ increases at a constant rate during the first 100 years from 1 to 3 , and remains 3 thereafter. In the study landscape, the amount of dead wood with bark is currently about twice as high in set-asides as in managed forests (Schroeder et al. 2007). The tree species factor, $T$, was set to $1,1.2$ and 0.75 for stands dominated by Norway spruce, deciduous trees and Scots pine, respectively. This reflects differences in tree mortality observed in mature managed forests in Sweden (Jonsson et al. 2010), and if everything else is equal the amount of dead wood is proportional to the tree mortality rate. The productivity factor, $P$, was included in the function because the volume of dead wood is approximately proportional to the site index (Ranius et al. 2003). The stand productivity was estimated as a site index corresponding to the tree height when the forest stand is 100 years old. Since the site index was on average 22, we obtained a mean value of 1 for $P$, by defining it as the site index divided by 22. 
In forest stands that are close to each other, habitat quality is likely to fluctuate over time in a correlated manner. We considered this by constructing a spatially explicit correlation structure in a similar manner to $\mathrm{Gu}$ et al. (2002), with modification of their algorithm because we used forest stands as spatial units, while Gu et al. (2002) used grids. The spatial correlation was represented hierarchically as follows. The study area was divided into four rectangles by randomly placing two lines. Each rectangle was further divided into four parts. This subdivision was done seven times. Each rectangle was given a random factor, $R_{\mathrm{ijk}}$, taken from a normal distribution with mean zero and variance $\delta^{2}$. The effective quality $A_{\mathrm{ij}}{ }^{*}(\mathrm{t})$, of forest stands with their midpoints within the grid cell $(i, j)$ at time $t$ was given by:

$$
A_{i j}^{*}(t)=A \exp \left(\sum_{k=1}^{7} c_{k} R_{i j k}\right)
$$

where $c_{\mathrm{k}}$ is a weight chosen to represent the strength of regional stochasticity at scale $k$ (from small to large scales). As input in the Monte Carlo simulations, we used three different sets of weights: $i$ ) regional stochasticity at all spatial scales, $\{1,1,1,1,1,1,1\}$; $i$ ) at the largest scale only, $\{0,0,0,0,0,0,1\}$; and iii) at the smallest scale only, $\{1,0,0,0,0,0,0\}$.

\section{Cited literature}

Ekbom, B., Schroeder, L.M., Larsson, S. 2006. Stand specific occurrence of coarse woody debris in a managed boreal forest landscape in central Sweden. Forest Ecology and Management 221, 2-12.

Gu, W., Heikkilä, R., Hanski, I., 2002 Estimating the consequences of habitat fragmentation on extinction risk in dynamic landscapes. Landscape Ecology 17, 699-710.

Jonsson, M., Ranius, T., Ekvall, H., Bostedt, G. 2010. Cost-effectiveness of silvicultural measures to increase substrate availability for wood-dwelling species: A comparison among boreal tree species. Scandinavian Journal of Forest Research 25, 46-60.

Ranius, T., Kindvall, O., Kruys, N., Jonsson, B.G. 2003. Modelling dead wood in Norway spruce stands subject to different management regimes. Forest Ecology and Management 182, 1329.

Schroeder, L.M., Ranius, T., Ekbom, B., Larsson, S. 2007. Spatial occurrence of a habitat-tracking saproxylic beetle inhabiting a managed forest landscape. Ecological Applications 17, 900909. 